\title{
Aspectos morfológicos, morfométricos e histoquímicos dos túbulos armazenadores de espermatozoides da fêmea do peru Meleagris gallopavo
}

[Histology, histochemistry, and morphometry of the tubuli spermatici of femeale turkeys, Meleagris gallopavo]

\author{
J.L.P.S. Miranda ${ }^{1}$, C.A. Oliveira ${ }^{2}$, G.A.B. Mahecha $a^{1,2^{*}}$ \\ ${ }^{1}$ Aluno de pós-graduação - PUC-Minas - Belo Horizonte, MG \\ ${ }^{2}$ Instituto de Ciências Biológicas - UFMG \\ Av. Antônio Carlos, 6627, Pampulha \\ 31270-901 - Belo Horizonte, MG
}

\begin{abstract}
RESUMO
Fragmentos da junção uterovaginal de 16 exemplares de fêmeas adultas de peru foram examinados, com o objetivo de determinar as modificações morfométricas e histológicas dos túbulos armazenadores de espermatozoides (SST), durante os períodos de atividade e repouso reprodutivo. Os estudos foram realizados a partir de dissecações do oviduto esquerdo, utilizando-se técnicas histológicas, histoquímica e histométricas de rotina. Essas estruturas originam-se de invaginações do epitélio das pregas da região uterovaginal e apresentam-se tubulosas, simples e não ramificadas, com epitélio formado por células prismáticas estreitas, claras e escuras, com núcleo vesiculoso basal e microvilos apicais. As secreções dessas células apresentaram reações negativas para PAS e Alcian Blue, indicando ausência de mucossubstâncias. Os parâmetros morfométricos utilizados mostraram que há diferenças significativas entre os períodos de atividade reprodutiva e de repouso. $\mathrm{Na}$ fase de atividade reprodutiva, o comprimento tubular, o volume tubular, o volume do lume, o número de SST na junção uterovaginal, o diâmetro externo e interno, a altura celular e o número de células por túbulos estão aumentados, e observam-se espermatozoides agrupados na luz do lume e células claras e escuras nos túbulos com vesículas supranucleares no citoplasma das células tubulares. Na fase de repouso, os parâmetros morfológicos estão reduzidos e não são encontrados espermatozoides na luz do lume. Nesta fase, não são evidenciadas as células escuras nem as vesículas supranucleares no citoplasma celular.
\end{abstract}

Palavras-chave: peru, fêmea, túbulos armazenadores, espermatozoide, morfometria

\begin{abstract}
Fragments of the uterus-vaginal junction of 16 adult female turkeys were investigated aiming to determine the morphometrical and histological modifications in the tubuli spermatici (tubular sperm glands) during the breeding (August to March) and non-breeding (April to July) seasons. The studies were performed in dissected oviducts processed for histology, histochemistry, and morphometry of the tubuli spermatici (TS), structures which are originated from invaginations of the uterus-vaginal epithelium. TS are simple tubular glands, lined by a columnar epithelium formed by light and dark narrow cells, which presented euchromatic nucleus and apical microvillus. The TS epithelium secretion was negative for PAS and Alcian Blue stains, indicating the absence of mucosubstances. The tubular length, tubular volume, luminal volume, number of TS, as well as external and internal diameter, cellular height, and number of cells per tubule showed significant differences between the reproductive phases (breeding and non-breeding). In the breeding season, all these morphometrical parameters were increased when compared with the ones from the non-breeding season. Clusters of sperm in the lumen of the glands, as well vesicles in the cytoplasm of both light and dark epithelial cells, were observed in the breeding season. In the non-breeding season, luminal sperm, vesicles, and dark cells were not observed in the TS glands.
\end{abstract}

Keywords: female, turkey, tubuli spermatici, spermatozoa, morphometry

Recebido em 20 de maio de 2008

Aceito em 15 de dezembro de 2008

*Autor para correspondência (Corresponding author)

E-mail: mahecha@icb.ufmg.br 


\section{INTRODUÇÃO}

Nas aves e na maioria dos répteis, como tartarugas, cobras e lagartos, após a cópula, os espermatozoides apresentam prolongada sobrevivência no oviduto, o que permite a sucessiva fertilização de ovócitos, sem a necessidade de novas cópulas (Birkead e Moller, 1992; Mello, 2000). Isso é atribuído, principalmente, à presença dos túbulos armazenadores de espermatozoides (SST), que são derivados epiteliais, localizados principalmente nas pregas longitudinais da transição uterovaginal do oviduto (Bakst, 1983; Bezuidenhout et al., 1995; Rodrigues, 1996; Mello, 2000).

O peru, Meleagris gallopavo, ave com marcada sazonalidade reprodutiva, é originário da América do Norte (Sibley e Monroe, 1990). Nessa espécie, os espermatozoides permanecem viáveis nos SST até 36 dias após uma única inseminação (Bakst, 1994). Nas aves sazonais, os SST apresentam modificações ao longo das fases de secreção, regressão, repouso e proliferação do ciclo reprodutivo. Entretanto, poucos estudos têm abordado as modificações morfométricas dos SST nos períodos de repouso e de atividade reprodutiva (Mero e Ogasawara, 1972).

Este trabalho teve como objetivo analisar as modificações histológicas e morfométricas dos SST, nos períodos de atividade e repouso do ciclo reprodutivo da fêmea do peru.

\section{MATERIAL E MÉTODOS}

Foram utilizadas 16 fêmeas de perus, adultas com diferentes e não conhecidas idades, de linhagens não selecionadas. Os exemplares foram adquiridos de criadores comerciais entre os anos de 2004 e 2006, durante os períodos de atividade reprodutiva (agosto a fevereiro) e repouso reprodutivo (abril a junho) no hemisfério sul. As aves foram sacrificadas por overdose de thiopental sódico ${ }^{1} \mathrm{e}$ submetidas à dissecação para localizar a região uterovaginal do oviduto. Essa região foi aberta dorsalmente e as pregas da mucosa foram contadas. A seguir, retiraram-se fragmentos longitudinais, destinados a análises histológicas, que foram fixados em líquido de Bouin (Lillie e Fullmer, 1976) durante 24 horas e, depois, incluídos em parafina ou glicol metacrilato, cortados de forma semisseriada com $5 \mu \mathrm{m}$ de espessura e corados pela hematoxilina e eosina, azul de toluidina $0,5 \%$ e borato de sódio $1 \%$.
Alguns desses fragmentos foram submetidos a colorações histoquímicas de: ácido periódico reativo de Schiff (PAS) (McManus, 1946); azul de alcian em pH 0,5 (Lev e Spicer, 1964); azul de alcian em pH 2,5 (Mowry, 1956); e digestão pela amilase salivar, seguida de PAS (Michalany, 1980).

Para estimar o número de SST de cada fêmea, inicialmente foram contadas as secções transversais dos SST, encontradas nos cortes longitudinais de 10 pregas da transição uterovaginal. A média dessas contagens foi multiplicada pelo número de pregas encontradas em cada região uterovaginal, obtendo, dessa forma, o número total médio de SST em cada ave. A seguir, foram medidos o diâmetro externo, o diâmetro do lúmen, a altura do epitélio e o número de células em 200 cortes transversais dos SST. Essas medidas foram realizadas utilizando-se régua micrométrica com escala conhecida, acoplada à lente ocular do microscópio de luz. O cálculo da altura do epitélio tubular foi realizado subtraindo-se do diâmetro tubular o diâmetro do lúmen, dividido por dois. $\mathrm{O}$ número de células de cada secção foi registrado por meio da contagem de seus núcleos.

A área dos SST foi calculada utilizando-se a fórmula da área da circunferência, e o comprimento foi determinado pela mensuração de 400 secções longitudinais dessas estruturas. O volume dos SST foi calculado multiplicando-se a área da seção transversal pela altura. Para comparação de médias dos dados utilizou-se teste $\mathrm{t}$ para duas amostras presumindo variâncias equivalentes $(\mathrm{P} \leq 0,05)$.

\section{RESULTADOS E DISCUSSÃO}

Nos períodos de atividade reprodutiva e de repouso, os SST foram localizados na junção uterovaginal do oviduto. As pregas da mucosa dessa transição e as estruturas nela contidas apresentaram variações morfológicas significativas entre os períodos estudados (Fig. 1A-F), semelhantes às descrições feitas em fêmeas de peru de exploração comercial (Ogasawara e Fuqua, 1972; Schupping et al., 1983), em galinha doméstica (Burke et al., 1971; Compton et al., 1977; Compton e Van Krey, 1978), em avestruz Strutio camelus (Bezuidenhout et al., 1995), em tentilhão Poephila guttata e Lonchura striata (Birkead e Hunter, 1990) e em codorna do campo Nothura maculosa (Rodrigues, 1996), mostrando que esse é o sítio primário de armazenamento de espermatozoides das aves. Segundo Bakst (1998), esses túbulos conservam os espermatozoides para fecundar os ovos de sucessivas ovulações.

${ }^{1}$ Cristália Prod. Quim. Farm. Ltda. - Itapira, Brasil. 
O número de pregas da junção uterovaginal foi de $38 \pm 1,4$, variando de 34 a 42 , mas não houve diferença significativa entre os períodos estudados quanto ao número de pregas. No período de atividade reprodutiva, essas pregas são altas e largas e, no período de repouso, são estreitas, baixas e finas. Goodrich-Smith e Marquez (1978) e Birkead e Moller (1992) verificaram que as peruas de exploração comercial apresentam de 24 a 25 pregas na junção uterovaginal. Esses autores não citaram a raça ou linhagem das peruas por eles estudadas, mas eram aves selecionadas para aumentar a produção de ovos. Esta seleção pode ter resultado na diminuição no número de pregas. Mello (2000), ao estudar a região uterovaginal de perdiz Rhynchotus rufescens, encontrou variação significativa no número de pregas da junção uterovaginal entre as fases reprodutivas. Essa variação foi de nove no período de repouso a 36 no período de atividade reprodutiva, demonstrando grandes modificações funcionais ao longo do período reprodutivo.

$\mathrm{Na}$ junção uterovaginal do oviduto, o epitélio é pseudoestratifidado prismático, formado por células ciliadas e não ciliadas que se alternam (Fig. 1A, B, C, D). Semelhante descrição foi encontrada no epitélio de codorna e de perdiz por Rodrigues (1996) e Mello (2000), respectivamente, não havendo formação de ductos diferenciados em nenhuma dessas espécies. Os SST encontram-se distribuídos ao longo das pregas da junção uterovaginal, em arranjo desordenado (Fig. 1A, B, D), semelhante às descrições realizadas por Christensen (1981), Schupping et al. (1983), Brillard e Bakst (1990), Bakst (1994, 1998), Freedman et al. (2001) e King et al. (2002). Algumas pregas apresentaram maior concentração de SST em relação às outras, e, mesmo dentro de uma prega, foram encontradas regiões com densidade maior de SST do que em outra (Fig. 1C e D). Este resultado difere dos encontrados por Birkead e Moller (1992), que verificaram os SST da fêmea do peru mais concentrados, na região intermediária das pregas da junção uterovaginal.

Os SST da fêmea do peru são glândulas tubulares, simples e não ramificadas, derivadas das invaginações do epitélio dessa região. O epitélio dos túbulos armazenadores de espermatozoides é formado por células prismáticas, não ciliadas, com núcleo basal, vesiculoso, elíptico, com nucléolo evidente (Fig. 1E, F). O citoplasma das células tubulares é acidófilo, sendo que a superfície apical apresenta trama terminal e projeções apicais sob a forma de microvilos, formando a borda estriada, vista através do microscópio óptico, descrição semelhante às feitas por Brillard e Bakst (1990), Rodrigues (1996), Mello (2000), Freedman et al. (2001) e King et al. (2002).

Os SST são formados por dois tipos celulares distintos, denominados de células claras e escuras. Verificou-se predomínio de células claras durante o período de atividade reprodutiva, semelhante às descrições feitas por Rodrigues (1996), em codornas, e por Mello (2000), em perdizes. Não foram observadas células escuras no período de repouso, fato não relatado na literatura consultada (Fig. 2F).

A natureza química das secreções, das células dos túbulos armazenadores de espermatozoides, não foi confirmada por meio de reações negativas aos métodos do ácido periódico-reativo de Schiff (PAS), PAS após a digestão pela amilase salivar e ao método de alcian blue em $\mathrm{pH} 0,5$ e 2,5, indicando ausência de mucossubstâncias carboxiladas, sulfatadas e glicoproteínas, ricas em ácido siálico. $\mathrm{O}$ mesmo ocorreu em galinha doméstica (Gilbert et al., 1968) e em codorna comum (Rodrigues, 1996), por isso essas estruturas não foram denominadas de glândulas hospedeiras de espermatozoides, termo utilizado por Compton e Van Krey (1978), em aves domésticas, por Schupping et al. (1983), em perus, e por Rodrigues (1996) e Mello (2000), em perdizes. Os resultados histoquímicos, como os de outros autores (Birkead et al., 1990; King et al., 2002), não demonstraram que essas estruturas tenham capacidade de secretar substâncias que possam nutrir os espermatozoides, por esse motivo elas não podem ser denominadas de glândulas.

Nos SST são encontradas vesículas vacuolizadas no citoplasma, em posição supranuclear, durante o período de postura (Fig. 1C, D). Estudos histológicos e histoquímicos demonstraram a presença de substâncias lipídicas nessas vesículas (Schupping et al., 1983) em peruas. É provável que o xilol utilizado nas preparações histológicas tenha retirado as gotículas lipídicas dessas vesículas como descrito por Tingary e Lake (1973). No período de repouso, durante os meses de abril a junho, essas vesículas vacuolizadas estão ausentes, fato que não é relatado na literatura consultada (Fig. 2C-F). Pal (1977), em patos, Renden et al. (1981), em codornas, e Schupping et al. (1983), em peruas, relataram a presença de vesículas vacuolizadas no citoplasma das células dos SST em posição supranuclear, durante o período de atividade reprodutiva. Friess et al. (1978) descreveram-nas como vesículas cheias de gotículas lipídicas em galinhas e codornas. 

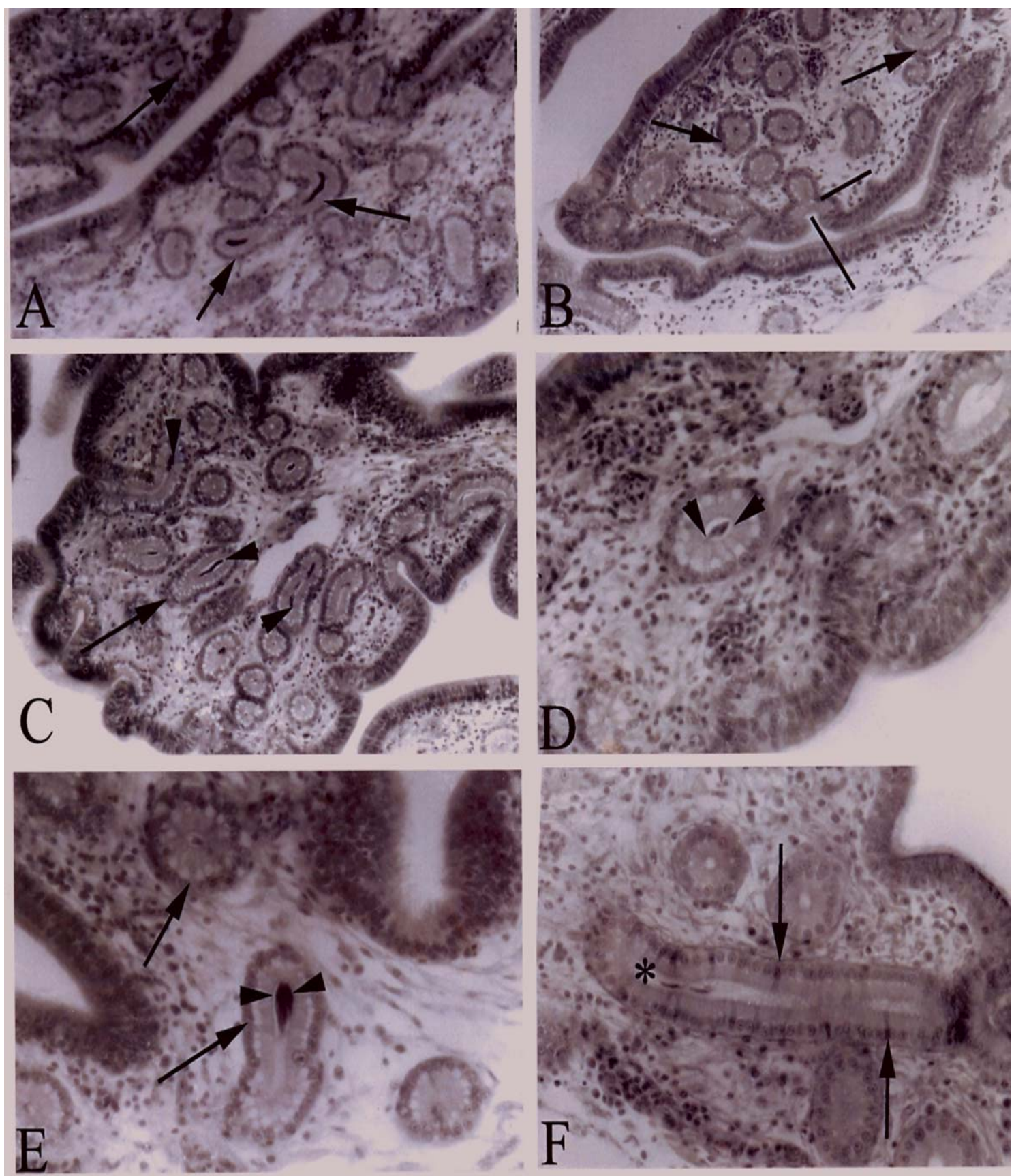

Figura 1. Aspectos morfológicos dos túbulos armazenadores de espermatozoides na região da junção uterovaginal da fêmea do peru Meleagris gallopavo, durante o período de atividade reprodutiva. A: Aspecto geral das pregas da região uterovaginal, evidenciado em diferentes cortes (secções) dispersos na lâmina própria (setas); B: prega da região uterovaginal com SST (setas) e invaginações do epitélio da prega, formando SST (ponta de seta); C: prega da região uterovaginal, com maior concentração de SST (seta), com espermatozoides no lume (cabeças de seta); D: Prega com menor concentração de SST com espermatozoides (cabeças de seta). E: SST na lâmina própria de uma prega da região uterovaginal (setas), repleto de espermatozoides em seu lume (cabeças de seta). F: SST em secção longitudinal (asterisco), evidenciando células escuras (setas) no meio das células claras. Células claras são mais frequentes, mas as escuras (setas) apresentam citoplasma com acidofilia mais intensa. (HE - A,B,C: 200X; D,E,F: 400X). 

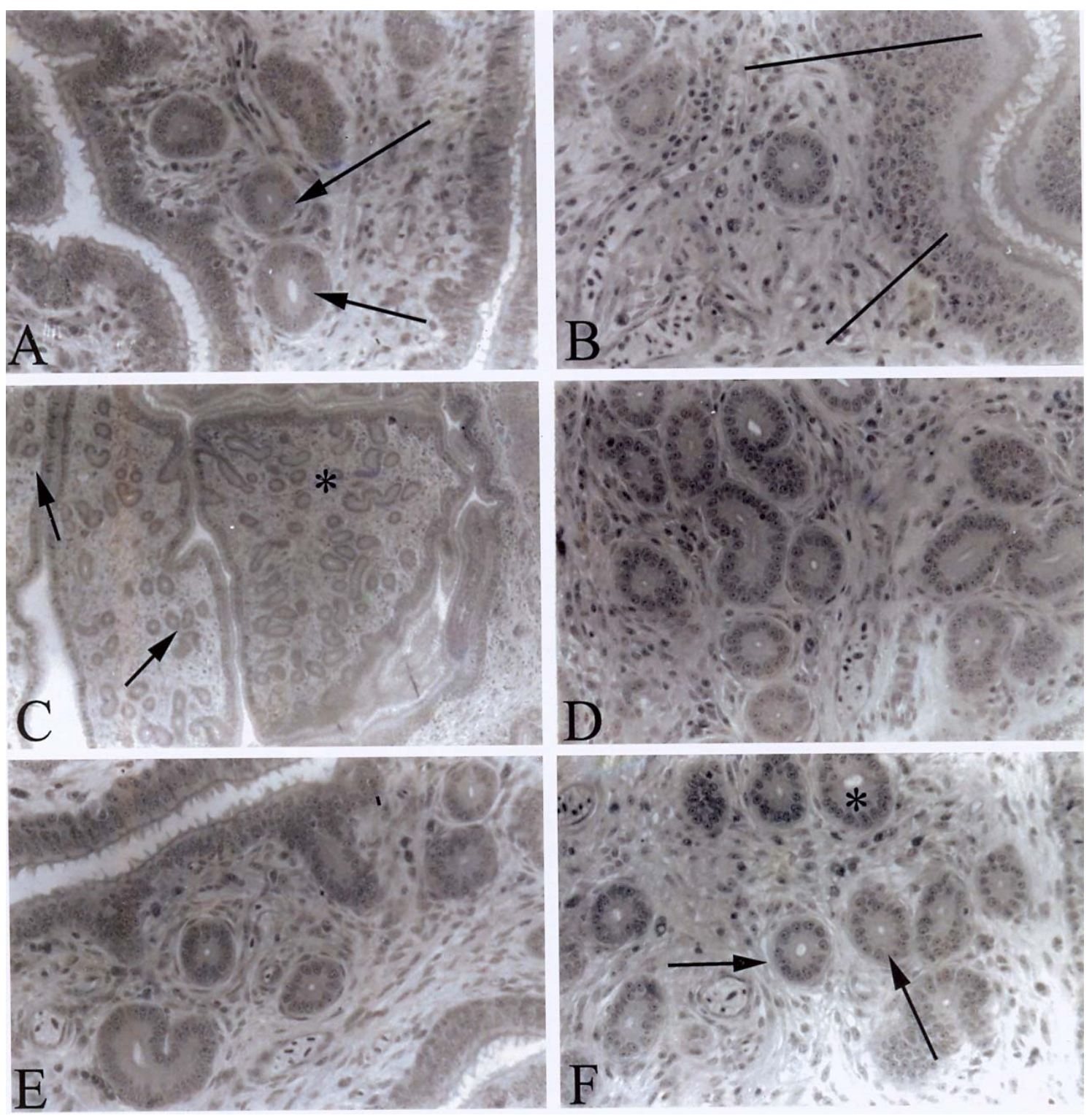

Figura 2. Aspectos morfológicos dos túbulos armazenadores de espermatozoides (SST) na região da junção uterovaginal (JUV) da fêmea do peru Meleagris gallopavo, durante o período de repouso reprodutivo. A: Aspectos gerais de três pregas da JUV com SST (setas) na lâmina própria; B: prega evidenciando o epitélio pseudoestratificado da JUV (pontas de seta) e poucos SST na lâmina própria; C: prega (asterisco) com maior concentração de SST e pregas laterais (setas) com menor concentração de SST; D: prega com grande concentração de SST na lâmina própria; E: prega com menor concentração de SST; F: prega evidenciando SST (setas), formado por apenas células claras, sem espermatozoides na luz (asterisco). Coloração: HE; A,B,D,E,F: 200X; C: 100X.

Em estudo com peru, Goodrich-Smith e Marquez (1978) encontraram 24.000 SST por região uterovaginal, e Birkead e Moller (1992), 20.000 dessas estruturas na região uterovaginal. No presente trabalho, foram encontradas (Tab. 1)
24.943 SST na região uterovaginal durante o período de postura e 23.795 no período de repouso. $\mathrm{O}$ número menor de $\mathrm{SST}$ no período de repouso é devido à renovação tubular que ocorre nessa época. 
Aspectos morfológicos, morfométricos...

Tabela 1. Dados morfométricos dos túbulos armazenadores de espermatozoides (SST) da fêmea do peru Meleagris gallopavo, durante os períodos de atividade e repouso reprodutivos, nos anos de 2004 e 2005 (Média e desvio-padrão).

\begin{tabular}{|c|c|c|c|c|c|c|c|c|}
\hline $\begin{array}{c}\text { Período } \\
\text { reprodutivo }\end{array}$ & $\begin{array}{c}\text { Diâmetro } \\
\text { tubular } \\
\text { externo } \\
(\mu \mathrm{m})\end{array}$ & $\begin{array}{c}\text { Diâmetro } \\
\text { tubular } \\
\text { interno } \\
(\mu \mathrm{m})\end{array}$ & $\begin{array}{c}\text { Comprimento } \\
\text { Tubular } \\
(\mu \mathrm{m})\end{array}$ & $\begin{array}{l}\text { Volume } \\
\text { tubular } \\
\left(\mu \mathrm{m}^{3}\right)\end{array}$ & $\begin{array}{l}\text { Volume } \\
\text { do lume } \\
\left(\mu \mathrm{m}^{3}\right)\end{array}$ & $\begin{array}{c}\mathrm{N}^{\mathrm{o}} \text { total } \\
\text { de túbulos }\end{array}$ & $\begin{array}{c}\mathrm{N}^{\circ} \text { de } \\
\text { células } \\
\text { tubulares }\end{array}$ & $\begin{array}{c}\text { Altura } \\
\text { celular } \\
(\mu \mathrm{m})\end{array}$ \\
\hline Atividade & $\begin{array}{c}42,29 \pm \\
6,98 \mathrm{a}\end{array}$ & $\begin{array}{c}5,325 \pm \\
1,89 \mathrm{a}\end{array}$ & $\begin{array}{c}655,17 \pm \\
91,08 \mathrm{a}\end{array}$ & $\begin{array}{c}942851,7 \pm \\
34698,7 \mathrm{a}\end{array}$ & $\begin{array}{c}16498,7 \pm \\
12932 \mathrm{a}\end{array}$ & $\begin{array}{c}24943,2 \pm \\
2411,9 \mathrm{a}\end{array}$ & $\begin{array}{c}14,00 \pm \\
2,8\end{array}$ & $\begin{array}{c}18,48 \pm \\
2,99 \mathrm{~b}\end{array}$ \\
\hline Repouso & $\begin{array}{c}34,46 \pm \\
4,92 \mathrm{~b}\end{array}$ & $\begin{array}{l}3,57 \pm \\
1,31 \mathrm{~b}\end{array}$ & $\begin{array}{l}531,29 \pm \\
107,36 \mathrm{~b}\end{array}$ & $\begin{array}{c}504960,3 \pm \\
185099,44 b\end{array}$ & $\begin{array}{c}6031,3 \pm \\
4613 \mathrm{~b}\end{array}$ & $\begin{array}{l}2379,57 \pm \\
2219,22 b\end{array}$ & $\begin{array}{c}11,54 \pm \\
1,91\end{array}$ & $\begin{array}{c}15,44 \pm \\
2,12 b\end{array}$ \\
\hline
\end{tabular}

Ab: Diferenças significativas entre os períodos de atividade e repouso reprodutivo (teste $\mathrm{t}-\mathrm{P} \leq 0,05$ ).

$\mathrm{Na}$ fase de atividade reprodutiva, o comprimento tubular dos SST foi, em média, $655,17 \mu \mathrm{m}$. No repouso, o comprimento tubular apresentou redução significativa, em média, $531,29 \mu \mathrm{m}$. Birkead e Moller (1992) descreveram que os SST nas fêmeas do peru são estruturas tubulares, não ramificadas, com comprimento de $1.000 \mu \mathrm{m}$, em média, diferentemente dos dados obtidos neste trabalho. Essas diferenças podem ser atribuídas ao fato de que esses autores não realizaram morfometria comparativa entre os períodos reprodutivos e utilizaram peruas brancas de peito largo, que são menores que as fêmeas utilizadas no presente trabalho. Por outro lado, a redução do comprimento tubular entre os dois períodos reprodutivos está relacionada à redução do citoplasma das células tubulares e da morte de algumas células tubulares que ocorre no período de repouso.

Nesta pesquisa, foram calculados os volumes tubular e do lúmen dos SST nos dois períodos estudados, parâmetros morfométricos não utilizados pelos autores consultados (Birkead e Moller, 1992). O volume tubular foi, em média, $942.851,7 \mu \mathrm{m}^{3}$, e o volume do lúmen, $16.498,7 \mu \mathrm{m}^{3}$, no período de atividade reprodutiva. No período de repouso, o volume tubular e o volume do lúmen foram, em média, $504.960,30 \mu \mathrm{m}^{3}$ e $6.031,32 \mu \mathrm{m}^{3}$, respectivamente, mostrando que a redução significativa do volume tubular e do volume do lúmen no período de repouso deve-se à diminuição do citoplasma das células tubulares. Os SST da fêmea do peru não chegam a desaparecer no período de repouso (Fig. 2A-F), como descrito por Mello (2000) em perdizes, e nem apresentam, nesse período, a intensa renovação dos SST, como nas codornas (Rodrigues, 1996). Por outro lado, apenas o número de células presentes nos SST não apresenta redução significativa entre os dois períodos reprodutivos.

O fenômeno do declínio sazonal da fertilidade da fêmea do peru é considerado inexplicável por Harper e Arscott (1969) e Wentworth et al. (1975). Considerando que os SST participam ativamente na fertilidade da fêmea do peru (Schupping et al.,1983; Brillard e Bakst, 1990), a redução significativa no volume dessas estruturas no período de repouso reprodutivo explica claramente o declínio da fertilidade sazonal dessas aves.

Os resultados do presente trabalho mostram que existe íntima relação entre o número e o volume dos SST com a fertilidade da fêmea de peru. Essas relações foram descritas em galinhas por Bakst (1998). A partir destes resultados, é plausível teorizar que peruas com maior numero e volume dos SST são mais férteis e que essas estruturas, sendo maiores e em maior quantidade, podem armazenar e viabilizar um maior número de espermatozoides para a fecundação dos ovócitos. Também é factível identificar e selecionar linhagens de peruas com SST maiores e mais numerosos visando tornar a prática de inseminação artificial mais eficiente, uma vez que esta é a metodologia mais utilizada na reprodução dessas aves. Dessa forma, os estudos morfométricos propostos neste trabalho servirão para avaliar a capacidade das peruas para armazenar maior número de espermatozoides.

Os conhecimentos adquiridos neste trabalho poderão contribuir para nortear estudos sobre a inseminação artificial desta espécie, uma vez que nestes processos é utilizado sêmen de alta fertilidade. Estes conhecimentos poderão, também, fornecer subsídios para estudos comparativos com outras espécies de aves. 


\section{REFERÊNCIAS BIBLIOGRÁFICAS}

BAKST, M.R. Fate of fluorescent stained sperm following insemination: New light on oviductal sperm transport and storage in the turkey. Biol. Reprod., v.50, p.987-992, 1994.

BAKST, M.R. Fate of turkey spermatozoa after intrainfundibular and intramagnal inseminations. J. Reprod. Fertil., v.67, p.315-317, 1983.

BAKST, M.R. Structure of the avian oviduct with emphasis on sperm storage in poultry. $J$. Exp. Zool., v.282, p.618-626, 1998.

BEZUIDENHOUT, A.J.; SOLEY, J.T.; GROENEWALD, H.B. et al. Sperm-storage tubules in the vagina of the ostrich (Struthio camelus). Onderstepoort J. Vet. Res., v.107, p.193-199, 1995.

BIRKEAD, T.R.; HUNTER, F.M. Numbers of sperm-storage tubules in the Zebra Finch (Poephila guttata) an Bengalese Finch (Lonchura striata). Auk, v.107, p.193-197, 1990.

BIRKEAD, T.R.; MOLLER, A.P. Sperm competition in birds: Evolutionary causes and consequences. London: Academic Press, 1992. $288 \mathrm{p}$.

BIRKEAD， T.R.; PELLAT, J.E.; HUNTER, F.M. Numbers and distribution of sperm in the uterovaginal sperm storage of the Zebra Finch. Condor, v.92, p.508-516, 1990.

BRILLARD, J.P.; BAKST, M.R. Quantification of spermatozoa in the sperm storage tubules of turkey hens and its relation to sperm numbers in the periviteline layer of eggs. Biol. Reprod., v.43, p.271-275, 1990.

BURKE, W.R.; OGASAWARA, F.X.; FUQUA, C.L. A study of the ultrastructure of the uterovaginal sperm-storage glands of the hen, Gallus domesticus, in relation to mechanism for the release of spermatozoa. J. Reprod. Fertil., v.29, p.29-36, 1971.

CHRISTENSEN, V.L. Effect of insemination interval on oviductal sperm storage in turkeys. Poult. Sci., v.60, p.2150-2156, 1981.

COMPTOM, M.M.; VAN KREY, H.P. A histological examination of the uterovaginal sperm storage glands in the domestics hen following in insemination with variable semen dosages. Poult. Sci., v.58, p.478-480, 1978.
COMPTOM, M.M.; VAN KREY, H.P.; SIEGEL. P.B. The filling and meeting of uterovaginal sperm-host glands in the domestic hen. Poult. Sci., v.57, p.1696-1700, 1977.

FREEDMAN, S.L.; AKUFFO, V.G.; BAKST, M.R. Evidence for the innervation of sperm storage tubules in the oviduct of the turkey (Meleagris gallopavo). Reproduction, v.121, p.809-814, 2001.

FRIESS, A.E.; SINOWATZ, F.; WROBEL, K.H. et al. The uterovaginal sperm host glands of the quail (Coturnix coturnix japonica). Cell Tissue Res., v.191, p.101-114, 1978.

GILBERT, A.B.; REYNOLDS, M.E.; LORENZ, F.W. Distribution of spermatozoa in the oviduct and fertility in domestics hen.: V. histochemistry of the uterovaginal sperm hosts glands of the domestic hen. J. Reprod. Fertil., v.16, p.433-444, 1968.

GOODRICH-SMITH, M.; MARQUEZ, B.J. Estimation of the numbers of sperm storage tubules located at the uterovaginal junction in turkey oviduct. Poult. Sci., v.57, p.1139, 1978. (Resumo).

HARPER, J.A.; ARSCOTT, G.H. Seasonal decline in fertility of turkey eggs. Poult. Sci., v.48, p.2109-2113, 1969.

KING, L.M.; BRILLARD, J.P.; GARRET, W.M. et al. Segretation of spermatozoa within sperm storage tubules of fowl and turkey hens. Reproduction, v.123, p.79-86, 2002.

LEV, R.; SPICER, S.S. Specific starning of sulphate groups with alcian blue at low $\mathrm{pH}$. $J$. Histochem. Cytochem., v.12, p.309, 1964.

LILLIE, R.D.; FULLMER, H.M. Histopatologic technic and practical histochemistry. 4.ed. New York: McGraw-Hill, 1976. 942p.

McMANUS, J.F.A. Histological demonstration of mucin after mucin after periodic acid. Nature, v.158, p.202, 1946.

MELLO, H.E.S. Aspectos morfológicos das glândulas hospedeiras de espermatozoides na perdiz, Rhynchotus rufescens (Temminck, 1815) (aves, Tinamiformes) nas fases do ciclo reprodutivo. 2000. 50f. Dissertação (Mestrado) Pontifícia Universidade Católica de Minas Gerais, Belo Horizonte. 
MERO, K.N.; OGASAWARA, F.X. Dimensions of uterovaginal sperm-storage tubules of the chicken and their possible significance in sperm release. Poult. Sci., v.49, p.1304-1308, 1972.

MICHALANY, J. Técnica histológica em anatomia patológica: com instrução para o cirurgião, enfermeiro e citotécnico. São Paulo: EPU, 1980. 277p.

MONRY, R.W. Alcian blue technic for the histochemical study of acid carbohydrates. $J$. Histochem. Cytochem., v.4, p.407, 1956.

OGASAWARA, F.X.; FUQUA, C.L. The vital importance of the uterovaginal sperm-host glands for the turkey hen. Poult. Sci., v.51, p.1035-1039, 1972.

PAL, D. Histochemistry of the uterovaginal junction with special reference to the sperm-host glands in the oviduct of the domestic duck. Folia Histochem. Cytochem., v.15, p.235-242, 1977.

RENDEN, J.A.; MAY, E.B.; BENOFF, F.H. Histochemistry of uterovaginal sperm-host glands in Japanese Quail (Coturnix coturnix japonica) with reference to the period of oviposition. Poult. Sci., v.60, p.2529-2535, 1981.
RODRIGUES, C.A.T. Morfologia do oviducto esquerdo da codorna comum, Nothura maculosa (Temminck, 1815) (aves, Tinamiformes), nas fases de secreção, regressão e proliferação. 1996. 229f. Dissertação (Mestrado) - Instituto de Ciências Biológicas, Universidade Federal de Minas Gerais, Belo Horizonte.

SCHUPPING, G.T.; VAN KREY, H.P.; DENBOW, D.M. Ultrastructural analysis of uterovaginal sperm storage glands in fertile and infertile turkey breeder hens. Poult. Sci., v.63, p.1872-1882, 1983.

SIBLEY, C.G.; MONROE Jr., B.L. Distribution and taxonomy of birds of the world. New Haven: Yale University, 1990. 1111p.

TINGARY, M.D.; LAKE, P.E. Ultrastructural studies on the uterovaginal sperm-host glands of domestic hen, Gallus domesticus. J. Reprod. Fertil., v.34, p.423-431, 1973.

WENTWORTH, B.C.; WINELAND, M.J.; PATON, G.D. Fertility of turkey hens correlated with depth of insemination. Poult. Sci., v.54, p.682-687, 1975. 